\title{
ANÁLISE DE RISCO PARA O CAFÉ EM MINAS GERAIS
}

\author{
Felipe do Lago Rugani ${ }^{1}$ \\ Suely de F. Ramos Silveira ${ }^{2}$
}

\begin{abstract}
Resumo - O café é um dos principais produtos da economia mineira, e em algumas regiões específicas pode-se notar maior intensidade na sua importância produtiva; contudo, em qualquer região os agentes envolvidos nesse mercado sempre se vêem diante de um problema: o nível de risco a que estão se expondo. Dessa forma, seria de grande utilidade uma ferramenta que avaliasse o risco que cada agente absorve. Assim, este trabalho indicou a medida do risco assumido pelos agentes envolvidos no mercado de café do estado, tendo como base os preços pagos na região sul mineira, a maior produtora, por meio de dois modelos do Value at Risk (VaR): o Normal e o de Simulação Histórica. Os resultados indicam que o risco absorvido pelos agentes de mercado chega a ser de $17,28 \%$ com $95 \%$ de confiança e de $24,60 \%$ com $99 \%$ de confiança, ambos para uma exposição de trinta dias, calculados pelo VaR Simulação Histórica, que se mostrou mais confiável. Além disso, a comparação com o cálculo do VaR do Ibovespa e do dólar evidenciou que o café apresenta maiores taxas de risco.
\end{abstract}

Palavras-chave: gestão de risco, VaR, cafeicultura.

\section{Introdução}

O café é um dos produtos mais tradicionais do ocidente e há tempos já se encontra enraizado na cultura de muitos países. No Brasil, das commodities mais negociadas do mercado, é a que apresenta a maior volatilidade (Aguiar, 2004).

$\mathrm{O}$ produto contribuiu significativamente na geração de recursos em território nacional, favorecendo as fases iniciais do processo de industrialização, criando empregos e renda no campo, gerando riquezas

\footnotetext{
Graduando em Administração pela Universidade Federal de Viçosa. E-mail: lagorugani@yahoo.com.br Professora Adjunta do Departamento de Administração da Universidade Federal de Viçosa.

E-mail: sramos@ufv.br
} 
neste espaço e impedindo o êxodo rural desordenado. Segundo Baer (1996), a força básica que apoiou o desenvolvimento industrial foi o incremento da cafeicultura com base na mão-de-obra imigrante livre. Os investimentos voltados para a infra-estrutura do setor cafeeiro proporcionaram um ambiente para uma produção industrial maior. A grande população imigrante empregada no setor cafeeiro, e em outros setores a ele relacionados, gerou um enorme mercado para bens de consumo baratos.

Para Gremaud et al. (1999), a urbanização e a industrialização do país tiveram parte de sua origem na irradiação do setor cafeeiro, especialmente depois da transição para o trabalho assalariado, que é um processo produtivo com efeito multiplicador maior que o da economia escrava.

As primeiras lavouras cafeeiras foram introduzidas no país há mais de dois séculos; historicamente, sempre houve protecionismo por parte do governo federal no que tange à produção nacional do grão. Entretanto, já há algum tempo o mercado de café vem sofrendo modificações, como o término do Acordo Internacional do Café (AIC) e do Instituto Brasileiro do Café (IBC), que, entre outras atribuições, visavam o controle de preços da commodity.

Em Minas Gerais, a cafeicultura tem importância destacada, principalmente depois da década de 1970, quando intempéries climáticas prejudicaram as lavouras paulista e paranaense, direcionando ainda mais a produção de café para este estado. As maiores regiões produtoras do estado, em ordem, são o Sul e Oeste de Minas, seguidos de Alto Paranaíba e Triângulo Mineiro, e Zona da Mata e Jequitinhonha.

Segundo dados do IBGE, Minas Gerais é responsável por 60,9\% de todo o café produzido no sudeste do país; além disso, o estado responde por $49,8 \%$ de toda a produção nacional da commodity, caracterizando a liderança nacional na produção do grão. Segundo dados da CONAB, as exportações da commodity, sozinhas, corresponderam a 6,70\% da balança de exportações do país em 2005, o que representou um aumento em relação a 2004 de 5,26\% e, em relação a 2003, de 5,04\%. 
De acordo com dados da ABIC (Associação Brasileira da Indústria do Café), na safra 2004/2005 o Sul de Minas Gerais foi responsável por cerca de $54 \%$ da produção estadual de café tipo arábica beneficiado, sendo, sozinho, responsável por cerca de $32 \%$ da produção nacional do mesmo produto, o que evidencia sua importância e sua liderança na produção da commodity. Ainda conforme dados da ABIC, na última década (1995/2005) o consumo interno nacional do café cresceu em média 5,28\%, e as exportações cresceram em média 5,5\%.

Segundo Leite (2001), os estados de Minas Gerais, Espírito Santo, São Paulo e Paraná são os maiores produtores de café no Brasil; o Espírito Santo é o maior produtor de café conillon, e Minas Gerais, de café arábica.

Um dos maiores problemas relacionados ao café está associado a baixos preços recebidos pelos produtores e sua instabilidade. Conforme Leite (2005), os preços do café no mercado internacional, quando elevados, apresentam grande volatilidade. No Brasil, historicamente, o produtor convive com momentos de preços altos e baixos.

Pelas características da cultura, torna-se muito difícil para o produtor ajustar rapidamente sua produção às alterações de mercado, de forma a tirar proveito de determinadas situações de curto e médio prazo. Ademais, a imprevisibilidade das variáveis climáticas e a existência de pragas, doenças e outros fatores tornam a previsão de produção e, conseqüentemente, dos preços complexa.

Uma ferramenta usual para redução do risco nessa atividade é o hedge, que, segundo Corrêa (2005), é a realização de uma operação que auxilie na administração do risco inerente à atividade, normalmente feita utilizando-se o mercado de derivativos - no caso, o mercado de derivativos agrícolas - a partir de posições que se compensam.

Cobiçado por sua rentabilidade, o café também sempre se destacou por variações cíclicas em sua cotação, que geralmente tende a cair até uma margem próxima ou abaixo dos custos de produção, provocando diminuição lenta da oferta, até que haja elevação brusca da sua cotação, 
que então provoca aumento da oferta até que a cotação entre em queda e inicie-se o ciclo novamente.

É importante lembrar que o setor agrícola é aquele em que se encontram características mais próximas às da concorrência perfeita, por apresentar, em alguns segmentos, a livre entrada e saída do setor, a atomicidade de cada produtor em relação ao mercado, o livre acesso à tecnologia e a homogeneidade dos produtos comercializados. Essa situação leva a um equilíbrio de longo prazo em que não haja lucros extraordinários, ou seja, o lucro do produtor será apenas o custo de oportunidade, que está incluído no custo econômico (Pindyck e Rubinfeld, 2002).

No Brasil, a produção cafeeira possui uma estrutura competitiva, ao passo que na comercialização o produtor defronta-se com um oligopsônio. Também no mercado de insumos o produtor defronta-se com mercados imperfeitos. Dessa forma, os cafeicultores brasileiros operam em um mercado imperfeito e em desequilíbrio, haja vista a maior oferta que a demanda do produto (Leite, 2005).

Dado o caráter intrínseco de imprevisibilidade da cafeicultura, o que se costuma fazer quanto à análise da rentabilidade ou risco da atividade é recorrer a análises de cenários ou análises de sensibilidade, associadas a cálculos pontuais de custos, que se restringem ao momento de sua aplicação. Tais práticas são limitadas pela sua simplicidade e linearidade analítica. Assim, uma ferramenta que viabilizasse a aplicação de técnicas mais complexas — que pudessem amenizar os problemas dos produtores e outros agentes participantes desse mercado - e que também fosse acessível aos pequenos produtores seria de grande valia para a economia do estado.

Portanto, no intuito de analisar a aplicação de um modelo mais completo de previsão de riscos no mercado de café, e visando auxiliar a alocação de recursos dos produtores no estado, este trabalho propõs-se a aplicar uma das mais avançadas técnicas de gestão de risco, desenvolvida e utilizada pelo mercado financeiro nas avaliações de riscos de 
investimentos: o VaR (Value at Risk). Visou-se testar sua adequação a análises dos riscos da commodity café, além de verificar qual a metodologia mais apropriada - o Modelo de Distribuição Normal ou o Modelo de Simulação Histórica - para avaliar o risco incorrido pelos agentes envolvidos no mercado cafeeiro em Minas Gerais.

\section{Referencial Teórico}

Todo empreendimento que visa lucro tem uma expectativa do retorno que pretende alcançar, o qual pode ser definido como "o total de ganhos ou prejuízos dos proprietários, decorrentes de um investimento num determinado período de tempo" (Gitman, 2004).

Atrelado ao retorno está o risco, que tem sido estudado e avaliado nas últimas décadas, quando a maioria dos mercados defrontou-se com aumento da variabilidade das cotações dos ativos. Segundo Gitman (2004), risco é a variabilidade associada à obtenção de retorno sobre algum investimento, ou seja, levando-se em consideração a possibilidade do retorno não existir, o risco é a probabilidade de haver retorno.

Para Jorion (1998), o risco é a volatilidade de resultados inesperados, normalmente relacionada ao valor de ativos e passivos de interesse, e as empresas estão expostas a três tipos de risco: operacional, estratégico e financeiro.

De acordo com Corrêa (2005), no mercado agrícola o risco de mercado "é o risco de perdas em função de flutuações adversas na cotação da commodity".

Markowitz (1952) afirmou que existem basicamente dois tipos de risco: sistemático e não-sistemático. $\mathrm{O}$ primeiro afeta a economia como um todo, de forma que não é possível eliminá-lo através de estratégias de diversificação, ao passo que o segundo afeta somente uma determinada empresa ou setor, e este sim pode ser reduzido a um valor aceitável, conforme a teoria de carteiras, desenvolvida pelo mesmo autor. 
Segundo Ross et al. (2002), "um risco sistemático é qualquer risco que afeta um grande número de ativos (...) um risco não sistemático é um risco que afeta especificamente um único ativo ou pequeno grupo de ativos".

Dessa forma, na conjuntura da produção do café, o risco que será analisado é o risco não-sistemático, ou específico, que afeta pontualmente o café e seu mercado.

Na tentativa de mensurar o risco e seus impactos, muitos modelos foram construídos, como os de análise de sensibilidade, análise de cenário, e maturity, que, ao longo do tempo, se mostraram de certa forma incompletos.

Assim, na década de 1980, Till Guldimann, então executivo do Banco J.P.Morgan, deu início ao desenvolvimento do VaR (Value at Risk), que é um modelo que descreve o percentil da distribuição de retornos projetada sobre um horizonte de tempo estipulado, sendo que, se $\boldsymbol{c}$ for o nível de confiança estipulado, o VaR corresponderá a (1-c), ou seja, o VaR sintetiza a maior perda esperada dentro de determinado período de tempo e intervalo de confiança (Jorion, 2003).

O VaR pode ser aplicado conforme a equação (1):

$\operatorname{VAR}(c, T)=E\left[F_{T}\right]-Q\left[F_{T}, c\right]$

em que:

c: nível de confiança;

T: espaço temporal;

$Q\left[F_{T}, c\right]:$ quartil correspondente ao nível de confiança $c ; \mathrm{e}$

$E\left[F_{T}\right]$ : esperança do futuro pagamento. 
Segundo Jorion (2003), o VaR pode ser utilizado tendo como base modelos paramétricos ou não-paramétricos.

Os modelos paramétricos são caracterizados pela utilização de distribuições de probabilidades predefinidas, com intervalos de confiança, e geralmente se apóiam na distribuição normal, na distribuição de erro generalizado ou na distribuição $t$ de Student. A principal crítica a esses modelos é a que a suposição da normalidade, ou simetria, na distribuição dos fatores de risco não é sustentada na dinâmica do mercado.

Os modelos não-paramétricos caracterizam-se por não fazerem uso de distribuições definidas a priori para a amostra em questão, o que reduz o nível de incerteza quanto ao seu resultado, acabando por resultar num VaR maior, visto que engloba possibilidades maiores de retornos extremos.

Parâmetros utilizados para verificar se a distribuição de qualquer amostra tem alguma relação com as distribuições supracitadas incluem o coeficiente de assimetria, que descreve os desvios em relação à simetria, e o coeficiente de curtose, que descreve o grau de achatamento da distribuição (Jorion, 2003).

Segundo Jorion (2003), tanto o Método de Simulação Histórica quanto o Método de Simulação de Monte Carlo não usam parâmetros predefinidos para expressar a sensibilidade das posições da carteira, sendo o VaR obtido através do isolamento dos percentis desejados.

Basicamente, para se descobrir a confiabilidade de cada modelo é utilizado o backtesting, que consiste na contagem do número de exceções, ou seja, conta-se o número de ocorrências negativas que superam o VaR em determinado período e com determinado intervalo de confiança, para uma dada amostra.

De acordo com o Bank for International Settlements, foram estabelecidos, através do Comitê da Basiléia de 1996, três níveis de confiabilidade para o VaR, nos quais o número de exceções é crescente 
e a confiabilidade decrescente, para uma amostra de 250 observações e para cada intervalo de confiança.

Assim, para um intervalo de confiança de $99 \%$ e 250 observações, temse:

- Zona verde: até 4 exceções

- Zona amarela: entre 5 e 9 exceções

- Zona vermelha: entre 10 e 15 exceções

Já para um intervalo de confiança de $95 \%$ e 250 observações, tem-se:

- Zona verde: até 17 exceções

- Zona amarela: entre 18 e 26 exceções

- Zona vermelha: entre 26 e 30 exceções

Sant'Anna e Rossi (2004) analisaram recentemente o efeito de cinco metodologias usualmente empregadas no cálculo do VaR em instituições financeiras que possuem ativos nos EUA e no Reino Unido e constataram que, após calcular o VaR através de cinco modelos (EQMA, EWMA, Histórico, Garch e Pareto), o modelo Histórico foi o que mostrou a melhor performance, ou seja, apresentou o menor número de falhas.

No presente trabalho, foram aplicados o VaR Normal e o VaR Método de Simulação Histórica, visando comparar um modelo paramétrico com um não-paramétrico, a fim de obter um conjunto de resultados que não fique refém das falhas intrínsecas de cada modelo, apontando o nível de risco no mercado de café, e um modelo mais adequado para sua medição. 


\section{Metodologia}

\subsection{Dados}

Visando captar as flutuações de preços no maior período possível, o período de análise escolhido compreende os anos de 1980 a 2005, totalizando vinte e seis anos, o que gera 312 observações. As cotações obtidas são as médias de cada mês do período analisado.

Trabalhou-se com a região Sul de Minas Gerais, por se tratar da maior produtora do estado. Os preços coletados são cotados em dólares, pagos ao produtor pela saca de $60,5 \mathrm{~kg}$ do café tipo arábica bebida dura, ou melhor. Tais cotações foram obtidas na Cooxupé (Cooperativa dos Produtores de Café de Guaxupé), empresa que conta com 10.664 cooperados e 1.455 colaboradores e recebe café produzido em mais de 100 municípios, localizados no Sul de Minas, Alto Paranaíba e Vale do Rio Pardo (estado de São Paulo).

As cotações do dólar americano e do Ibovespa, entre agosto de 2005 e julho de 2006, foram obtidas no banco de dados da BOVESPA (www.bovespa.com.br).

\subsection{Procedimentos Empíricos}

Primeiramente, é necessário ressaltar que, por se tratar de uma commodity, o café tem sua formação de preço no mercado internacional, e ela independe das flutuações de preços ocorridas no mercado interno. Assim, foram utilizados os preços de mercado cotados em dólares americanos, com o objetivo de minimizar as distorções na análise.

Como a análise não trata de sistemas de produção ou de custos de produção, restringindo-se somente aos preços recebidos pelos produtores de café na região do Sul de Minas e ao risco inerente às suas flutuações, não se consideraram as variações de produtividade. Assim, assumiu-se 
que o preço de mercado absorve todas as informações disponíveis sobre o ativo (Pinheiro, 2005).

O primeiro passo para análise foi a obtenção do histograma com a distribuição de freqüência de ocorrência de cada intervalo de valor na série de dados - a série de preços. Em seguida, os dados foram tratados estatisticamente, sendo calculados a média, o erro-padrão, o desvio-padrão, a variância, o coeficiente de curtose e a assimetria da amostra.

Para o cálculo do VaR, o período de exposição ao risco foi considerado o de 30 dias, a fim de facilitar o cálculo e sua aplicabilidade para os agentes de mercado. Assim, estimou-se o VaR Normal para 30 dias, através da equação (1), multiplicando-o por 2,326 para $99 \%$ de confiança e por 1,645 para $95 \%$ de confiança.

Posteriormente, calcularam-se as variações mensais conforme a equação (2):

$$
V=\frac{D_{t}}{D_{t-1}}
$$

em que:

$D_{t}$ : preço pago pelo café na data t; e

$D_{t-1}$ : preço pago pelo café na data $\mathrm{t}-1$.

Então, identificaram-se os percentis correspondentes aos níveis de $99 \%$ e $95 \%$ de confiança, encontrando então o VaR Simulação Histórica, para 30 dias.

Fez-se ainda o backtesting para os intervalos de confiança de $95 \%$ e 99\% do Modelo de VaR Normal e VaR Simulação Histórica, através da rolagem de uma janela de 250 observações, da primeira cotação até a 
última, obtendo-se os números de exceções de cada modelo, possibilitando a comparação da confiabilidade dos modelos com as recomendações do Comitê da Basiléia e em relação um ao outro.

Calculou-se, para efeito de comparação, o VaR Simulação Histórica do índice Ibovespa e o dólar americano, ambos no período compreendido entre agosto de 2005 e julho de 2006, pra uma exposição de 30 dias.

Finalmente, os resultados obtidos foram comparados e explicitados por meio de tabelas e gráficos.

\section{Resultados e Discussão}

\subsection{Evolução dos Preços}

A evolução histórica dos preços recebidos pelos produtores na região Sul de Minas Gerais demonstra elevada variabilidade ao longo do período analisado (Gráfico 1), o que ressalta o caráter de alto risco e volatilidade do mercado do café.

Além disso, pode-se verificar um indício de comportamento cíclico na cotação, que apresenta bruscos aumentos a cada período aproximado de oito ou nove anos. 


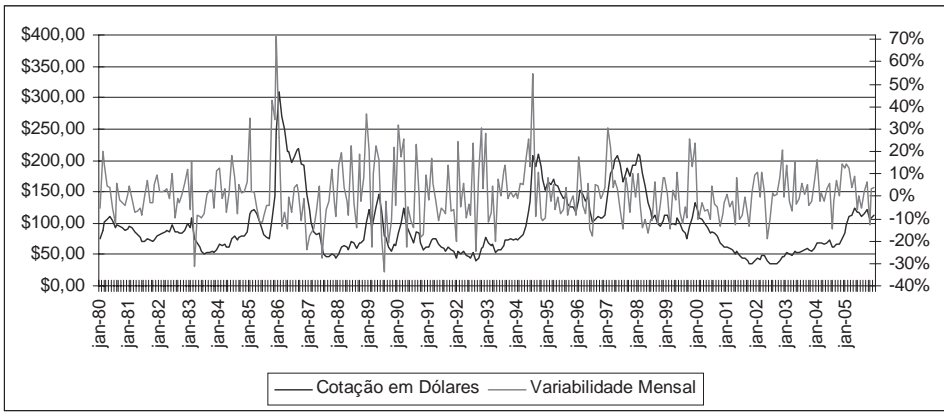

Gráfico 1 - Cotação dos preços recebidos pelos produtores e sua variabilidade mensal, de 1980 a 2005.

Fonte: Dados da pesquisa.

Assim, o caráter volúvel das cotações da commodity em questão fica evidente, conforme representado no Gráfico 1.

Aplicando a equação (2), obtiveram-se as variabilidades mensais das cotações, identificando-se que os preços têm variabilidade média mensal de $9,43 \%$.

A fim de verificar a frequiência dos preços obtidos e visualizar a distribuição de freqüência de preços, criou-se um histograma (Gráfico 2), o qual permitiu identificar que valores menores ocorrem com maior frequiência e deslocados à esquerda da média (U\$ 95,17), o que implica maior cuidado na aferição do risco, pois valores menores ocorrem mais freqüentemente. 


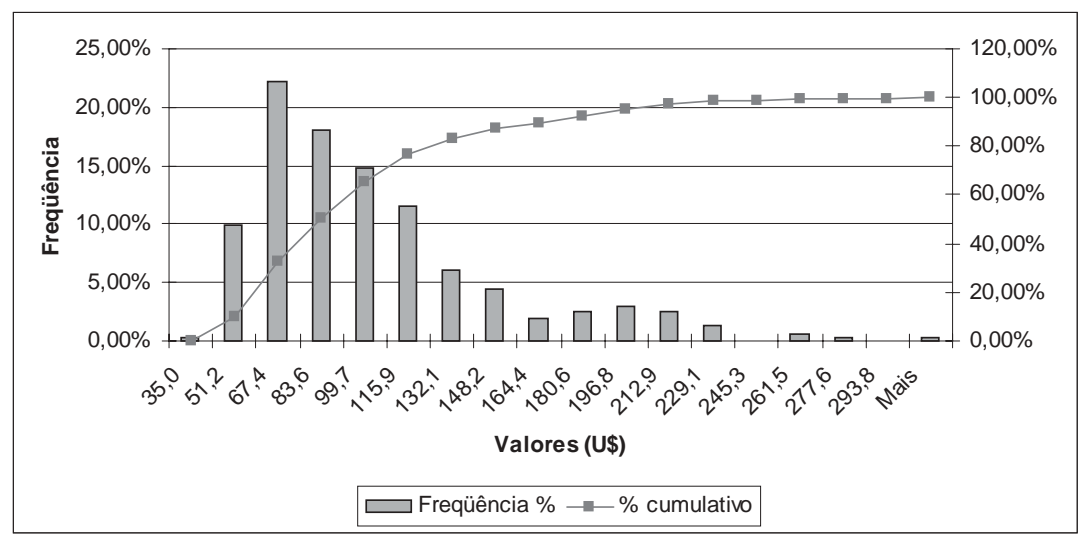

Gráfico 2 - Histograma dos preços recebidos pelos produtores, suas freqüências de ocorrência e valor acumulado.

Fonte: Dados da pesquisa.

Pelo resultado do coeficiente de assimetria (Tabela 1), nota-se que a distribuição em questão realmente não segue os mesmos padrões de uma distribuição normal, que tem esse índice igual a zero.

Além disso, o resultado do coeficiente de curtose corrobora essa afirmativa, pois esse índice é igual a 3 numa distribuição normal. 
Tabela 1 - Valores estatísticos da amostra

\begin{tabular}{lc}
\hline Variável & Valor \\
\hline Média (US\$) & 95,165 \\
Erro-padrão (US\$) & 2,669 \\
Desvio-padrão (US\$) & 47,143 \\
Variância da amostra (US\$) & 2222,467 \\
Curtose & 2,176 \\
Assimetria & 1,452 \\
Mínimo (US\$) & 35,040 \\
Máximo (US\$) & 309,970 \\
Contagem (ud) & 312,000 \\
Maior(1) & 309,970 \\
Menor(1) & 35,040 \\
\hline
\end{tabular}

Fonte: Dados da pesquisa.

\subsection{Valores para o VaR Normal}

No calculo do VaR Normal obteve-se um nível de risco de 15,51\% para 95\% de confiança e de $21,93 \%$ para $99 \%$ de confiança (Tabela 2), demonstrando ao produtor que seu risco permanece proporcionalmente o mesmo, independentemente do nível de investimento, o que não justifica posturas conservadoras quanto ao aumento no valor do investimento. 
Tabela 2 - Valores do risco para o VaR Normal, em dólares e em percentual

\begin{tabular}{ccc}
\hline \multicolumn{3}{c}{ VaR Normal } \\
\hline \multirow{2}{*}{ Investimento } & \multicolumn{2}{c}{ Nível de Confiança } \\
\cline { 2 - 3 } & $95 \%$ & $99 \%$ \\
\hline $25.000,00$ & $\$ 3.878,09$ & $\$ 5.483,55$ \\
$\$ 50.000,00$ & $\$ 7.756,18$ & $\$ 10.967,09$ \\
$\$ 100.000,00$ & $\$ 15.512,35$ & $\$ 21.934,18$ \\
Percentual de risco & $15,51 \%$ & $21,93 \%$ \\
\hline
\end{tabular}

Fonte: Dados da pesquisa.

O resultado do backtesting do VaR Normal apontou um número de exceções elevado, tanto para o intervalo de confiança de $95 \%$ quanto para o de $99 \%$ (Tabela 3), extrapolando a Zona Verde de confiabilidade (de até 17 e até 4 exceções, respectivamente) indicada pelo Comitê da Basiléia.

Tabela 3 - Número de exceções para o VaR Normal

\begin{tabular}{lcc}
\hline \multicolumn{3}{c}{ Backtesting - VaR Normal } \\
\cline { 2 - 3 } & \multicolumn{3}{c}{ Nível de Confiança } \\
\hline Número de Exceções & 19 & $99 \%$ \\
\hline
\end{tabular}

Fonte: Dados da pesquisa.

\subsection{Valores para o VaR Simulação Histórica}

O VaR Simulação Histórica mostrou valores maiores de risco (Tabela 4). Esse resultado, de certa forma, pode ser explicado pelo fato de que o modelo não usa uma distribuição predefinida, então não incorre no erro da "cauda fina", usual nos modelos paramétricos, que subestimam o risco por pressuporem frequiências de ocorrência menores para valores extremos, o que, de fato, não ocorre na dinâmica do mercado. 
Em verdade, o que se observa no mercado é a ocorrência de séries de cotações que não seguem padrões. Essas cotações flutuam em torno de preços mínimos, planos de suporte, e preços máximos, planos de resistência, o que é corroborado pelo trabalho de Pinheiro (2005).

Tabela 4 - Valores do risco para o VaR Simulação Histórica, em dólares e em percentual

\begin{tabular}{crr}
\hline \multicolumn{3}{c}{ VaR Simulação Histórica } \\
\cline { 2 - 3 } Investimento & \multicolumn{2}{c}{ Nível de Confiança } \\
\cline { 2 - 3 } & $95 \%$ & $99 \%$ \\
$\$ 25.000,00$ & $\$ 4.319,70$ & $\$ 6.151,05$ \\
$\$ 50.000,00$ & $\$ 8.639,40$ & $\$ 12.302,10$ \\
$\$ 100.000,00$ & $\$ 17.278,80$ & $\$ 24.604,20$ \\
\hline Percentual de risco & $17,28 \%$ & $24,60 \%$ \\
\hline
\end{tabular}

Fonte: Dados da pesquisa.

O resultado do backtesting do VaR Simulação Histórica indicou um número de exceções aceitável para os padrões da Zona Verde de segurança, tanto para 95\% quanto para 99\% de confiança (Tabela 5).

Tabela 5 - Número de exceções para o VaR Simulação Histórica

\begin{tabular}{lcc}
\hline \multicolumn{3}{c}{ Backtesting - VaR Simulação Histórica } \\
\hline & \multicolumn{2}{c}{ Nível de Confiança } \\
\cline { 2 - 3 } & $95 \%$ & $99 \%$ \\
\hline Número de Exceções & 16 & 4 \\
\hline
\end{tabular}

Fonte: Dados da pesquisa. 


\subsection{Comparações}

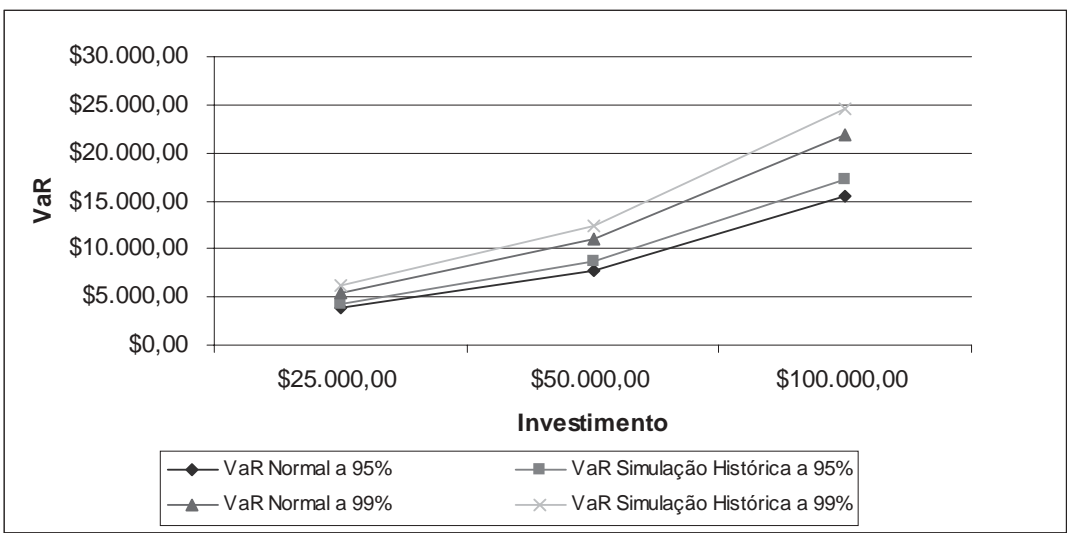

O VaR que cada modelo aferiu ao produtor de café, para cada nível de confiança e cada nível de investimento, por 30 dias, pode ser visualizado no Gráfico 3. Verifica-se que o VaR Normal sempre retorna um valor de risco bem menor que o VaR Simulação Histórica, subestimando o risco inerente ao mercado. 
Gráfico 3 - Comparação entre os modelos de VaR aplicados.

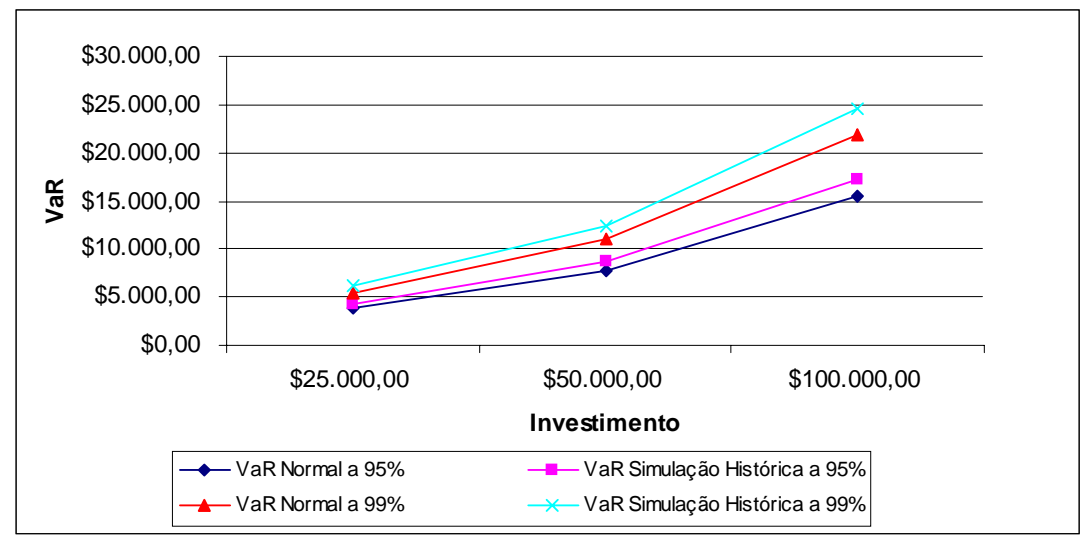

Fonte: Dados da pesquisa.

Com os resultados observados, percebe-se que o VaR Simulação Histórica se mostrou mais confiável, por apresentar menor número de exceções, demonstrando melhor aferição do risco absorvido.

Por meio do Gráfico 4, pode-se ver a comparação que expressa o nível de risco absorvido para o café, o Ibovespa e o dólar, todos para uma exposição de 30 dias, calculados pelo VaR Simulação Histórica com confiabilidades de $95 \%$ e $99 \%$, respectivamente. 


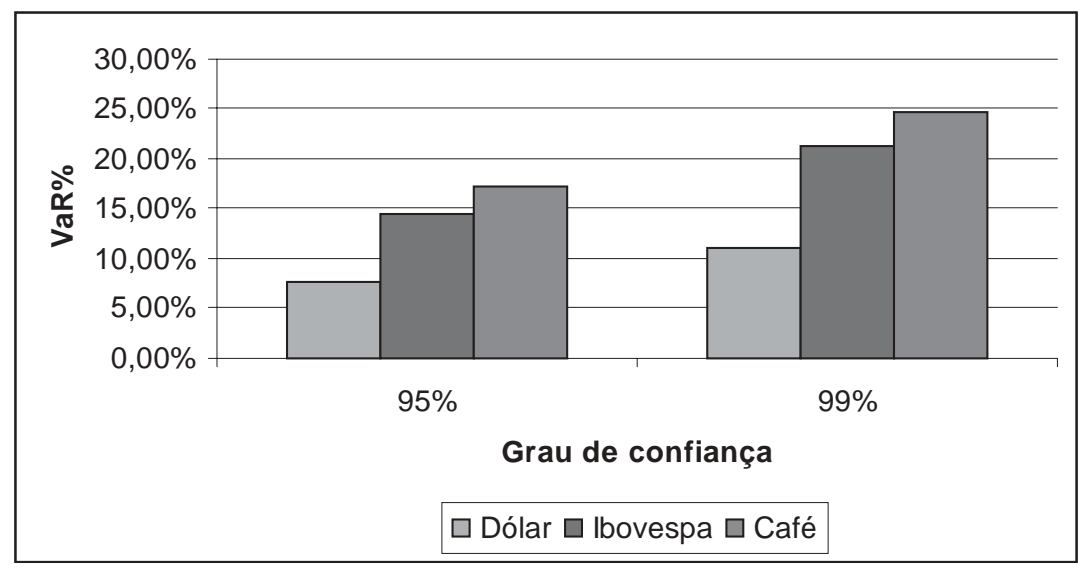

Gráfico 4 - Comparação entre o VaR Simulação Histórica do dólar, Ibovespa e café.

Fonte: Dados da pesquisa.

Pode-se ver que o café apresentou as maiores taxas de risco, tanto para 95\% quanto para $99 \%$ de confiança, o que revela seu caráter volúvel, mesmo quando comparado a indicadores como o Ibovespa e o dólar, os quais, segundo Pinheiro (2005), apresentam historicamente alta variabilidade.

\section{Conclusão}

Com os resultados, verificou-se que a distribuição da amostra em questão não segue os mesmos parâmetros de uma distribuição normal, o que inviabiliza a utilização de qualquer modelo paramétrico que, como tal, faça uso de uma distribuição predefinida. Além disso, o uso do VaR Normal provou ser mais falho, ou menos eficaz, quanto à sua confiabilidade. 
O VaR Simulação Histórica mostrou-se o mais apto para essa análise, corroborando a idéia de que métodos não-paramétricos têm melhor capacidade de mensuração de risco. Além do mais, provou ser mais confiável na mensuração do risco, apresentando menor número de exceções.

Foi possível observar que o risco absorvido pelos agentes que fazem parte do mercado cafeeiro ficou em torno de $17,28 \%$, considerando um intervalo de confiança de $95 \%$, e de $24,60 \%$, em intervalo de $99 \%$ ambos os resultados para uma exposição de 30 dias. Isso significa dizer que, para um investimento de U $\$ 25.000,00$, há $99 \%$ de probabilidade de o agente não perder mais que U\$6.151,05 durante um mês, o que representa, por si só, um valor de risco relativamente alto.

Os resultados mostram também que o mercado de café é mais volátil e proporciona maiores taxas de risco que o dólar e o Ibovespa, que são sabidamente voláteis. Assim, os agentes envolvidos diretamente no mercado de café estão assumindo riscos altos.

Com este trabalho, espera-se ter contribuído para incentivar o uso de modelos de análise de risco, como o VaR, para auxiliar na tomada de decisão dos agentes envolvidos no mercado de commodities, em especial o café.

\section{Referências}

Associação Brasileira da Indústria do Café - ABIC. Disponível em $<$ http://www.abic.com.br > . Acesso em: 08/08/2006.

AGUIAR, D. R. D. Agricultural futures contracts in Brazil: evolution and perspectives. In: MOURA, A. D.; SILVA JUNIOR, A. G. (editores). Competitividade do Agronegócio brasileiro em mercados globalizados. Viçosa, 2004.

BAER, W. A Economia Brasileira. São Paulo: Nobel, 1996. 
BASLE COMMITEE ON BANKING SUPERVISION. Supervisory Framework for the Use of "Backtesting" in Conjunction with the Internal Models Approach to Market Risk Capital Requirements. Basle: Bank For International Settlements, 1996.

Bolsa de Valores de São Paulo - BOVESPA. Disponível em <http:// www.bovespa.com.br>. Acesso em: 20/05/2006.

Companhia Nacional de Abastecimento - CONAB. Disponível em $<\underline{\text { http:/ }}$ /www.conab.gov.br >. Acesso em: 18/03/2006.

Cooperativa dos Produtores de Café de Guaxupé - COOXUPÉ. Disponível em <http://www.cooxupe.com.br> $>$. Acesso em: 20/03/2006.

CORREAA, A. L.; RAÍCES, C. Derivativos Agrícolas. São Paulo: Globo, 2005.

GITMAN, L. J. Princípios de administração financeira. 10. ed. São Paulo: Addison Wesley, 2004.

GREMAUD, A. P.; VASCONCELOS, M. A. S.; TONETO, R. Economia brasileira contemporânea. 3. ed. São Paulo: Atlas, 1999.

Instituto Brasileiro de Geografia e Estatística IBGE. Disponível em $<$ http:/ /www.ibge.gov.br>. Acesso em: 21/03/2006.

JORION, P. Value at Risk: a nova fonte de referência para a gestão do risco financeiro. São Paulo: BM\&F, 2ed., 2003.

JORION, P. A nova fonte de referência para o controle do risco de mercado - Value at Risk. São Paulo: BM\&F, 1998.

LEITE, C. A. M. Avaliação da cafeicultura nos últimos anos. Carlos Antônio Moreira Leite. Viçosa, 2005. 56 p. 
LEITE, J.L.F. Brasil: o gigante do café. Disponível em <http:// www.cafe.com.br/trabalho $>$.Acesso em: 29/03/2006.

MARKOWITZ, H. Portfolio selection. The Journal of Finance, v. 7, n. $1,1952$.

PINDYCK, R. S., RUBINFELD, D. L. Microeconomia. São Paulo: Prentice Hal, 5a ed., 2002.

PINHEIRO, J. L. Mercado de Capitais: fundamentos e técnicas. São Paulo: Atlas, 2005, 3.ed.

ROSS, S. A.; WESTERFIELD; R. W.; JAFFE, J. F. Administração financeira. São Paulo: Atlas, 2002.

SANT'ANNA, A. S., ROSSI, L. E. M. Análise das metodologias de VaR - Value at Risk - para estimar o risco de mercado de ativos brasileiros. In: SEMINÁRIO DE ESTUDOS EM ADMINISTRAÇÃO, VII, 2004. São Paulo: Semead, 2004.

\begin{abstract}
The coffee is one of the most important products in the economy of Minas Gerais. In some specific places it has a great importance in the local production, but in any place the economic players involved in that market have the same trouble: the share of risk taken by them. Therefore, would be really important, and useful, to calculate the risk share of each player. Than, this article showed the risk amount absorbed by the players in the coffee market of Minas Gerais, based in the prices paid in the south of that state, the greatest region producer, trough two models of Value at Risk (VaR), the Normal Model and the Historic Simulation Model. The results shows a risk absorbed about $17,28 \%$, with $95 \%$ of sure, and $24,60 \%$ with $99 \%$ of sure, both of them in a thirty days exposure, calculated by the Historic Simulation VaR Model, which was the most trustable, with less exceptions. Besides, the compare between the risks of coffee, Ibovespa and dollar, all of them calculated by VaR Historic Simulation, evidence the coffee as the most risk full of them, with the greatest amount of risk value.
\end{abstract}

Key words: Risk Management, VaR, Coffee. 